\title{
The Strategic Effectiveness of Accounting Information Systems in Achieving Security in Light of Electronic Commerce: A Case Study of Jordanian Banks
}

\author{
DYALA MOHAMMAD AL DEBEI \\ Instructor, Electronic Academy of Balqa, Balqa Applied University, Al Salt - Jordan.
}

EMAN AHMAD AL HANINI

Associate Professor, Department of Accounting, Faculty of Business, Balqa Applied University, Al Salt - Jordan.

Email: Eman.hanini@bau.edu.jo

\begin{abstract}
The aim of this study was to identify the strategic effectiveness of accounting information systems in achieving security in the light of electronic commerce. The analytical descriptive method was used to select a simple random sample of (25\%) of the total population of the study. The sample consisted of 309 respondents to the questionnaire which was used as a data collection tool. Three hundred questionnaires were valid for analysis. Nine questionnaires were rejected for failure to meet the requirements. The percentage of questionnaires recovered was valid for analysis by 97\%, which is acceptable for achieving the objectives of the study. After conducting the statistical analysis, the study reached a number of results, the most prominent of which were: The level of strategic efficiency of accounting information systems in Jordanian commercial banks was medium, the problems that arise through the application of accounting information systems in Jordanian commercial banks were medium, And that the degree of personal practice of e-commerce in Jordanian commercial banks was medium. The study also found a statistically significant relationship at the level of significance $(\alpha=0.05)$ for the strategic effectiveness of accounting information systems and achieving security in the light of electronic commerce. The study mentioned several recommendations, the most important of which was the need to activate the accounting information systems in various commercial banks in order to be able to practice control on these banks, manage to protect the customers' property and develop the work in these banks.
\end{abstract}

Keywords: Strategic Effectiveness, Accounting Information Systems, Electronic Commerce, Reliability, Security.

\section{Introduction}

One of the consequences of globalization is that it allowed people to open up at each other in political, economic and social fields. The economic development resulted in the emergence of large projects and enterprises as well as multinational banks and companies all of which aimed at achieving strategic effectiveness in the world market. These companies and banks basically differed in terms of their objectives. Yet, with the emergence of the term "E-commerce', it turned out that banks and companies necessarily required the use of information system which can easily provide electronic information that to obtain the benefits and objectives that they aim to achieve via e-commerce. 
Interestingly, accounting information system is one of the core elements that can provide important information. The thing that diminishes the credit risks that companies and bank face. These systems can quickly access and make a set of accounting calculations, provide information and make programmed control tests through which it can be assured that the conditions have been met via the system. Some of these conditions are to examine the higher line of credit and make sure that accounting data processing was done according to the international standards to obtain the most accurate financial reports. The present study is therefore set to recognize the strategic effectiveness of accounting information system in achieving reliability through E- commerce in the Jordanian banks.

\section{Objectives of the Study}

The present study aims at the following:

1. Presenting the level of the strategic effectiveness in Jordanian banks.

2. Identifying the problems that appear through applying accounting information system in Jordanian banks.

3. Presenting the extent to which people practice E- commerce in Jordanian banks.

4. Defining if there is a statistically significant correlation at $(\alpha=0.05)$ level for the strategic effectiveness of accounting information system in achieving reliability through E- commerce in Jordanian banks.

5. Defining if there is a statistically significant correlation at $(\alpha=0.05)$ level for the strategic effectiveness of accounting information system and achieving reliability through E- commerce in Jordanian banks that can be attributed to demographic variables.

\section{The Importance of the Study}

1. From a theoretical point of view: this study theoretically draws its importance from the important information related to the strategic effectiveness of accounting information systems that will be obtained from various resources as well security granted through E-commerce. These points are two of the important variables in the field of accounting management.

As far as the researchers know, this study is the first of its kind to deal with the strategic effectiveness of accounting information system and achieving security in E- commerce which can add to the accounting library. This study is also to shed light on the problems and difficulties that can result from accounting information system in E- commerce.

2. From a practical point of view: Practically, this study can benefit the following:

a. Employees at commercial banks will recognize the role of strategic effectiveness of accounting information system for the security purposes via E- commerce.

b. Researchers may take this study as the starting point for further research about the same issue. Valuable results can enrich the frame under which these studies are befallen.

c. Those who are interested in the area of management and accounting will also benefit from the studying the role of strategic effectiveness in achieving security via E- commerce.

\section{Problem of the Study}

People usually do not continue dealing with companies through E- commerce because of mistrust. They often believe that there leaks in information through accounting information system. In addition to that, the information that is provided to dealers might not be reliable. However, these fears should vanish with the use of surveillance and controlling systems for the information accounting and everything that is related to E- commerce. This might grant credibility and reliability in dealing with E- commerce and is one of the objectives of the present study. The main problem of the study is to answer the main research question 
which is: "What is the role of strategic effectiveness in achieving security in E- commerce?" The study will attempt to answer the following sub-questions:

1. What is the level of strategic effectiveness in Jordanian banks?

2. What are the problems that can result from applying accounting information system in Jordanian banks?

3. To what extent do personnel practice E- commerce in Jordanian banks?

4. Is there is a statistically significant correlation at $(\alpha=0.05)$ level for the strategic effectiveness of accounting information system in achieving reliability through E- commerce in Jordanian banks?

5. Is there a statistically significant relationship at the level of significance $(\alpha=0.05)$ for the strategic effectiveness of accounting information systems and achieving security in the light of e-commerce due to demographic variables?

\section{The Study Model}

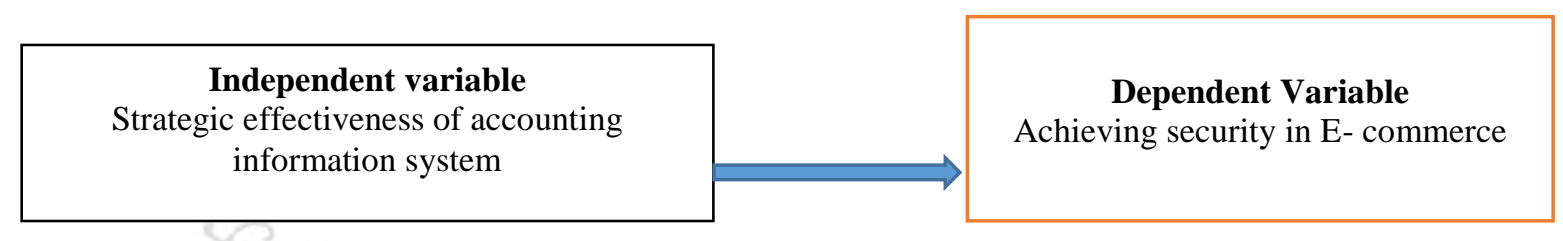

Figure (1) Study Model

\section{Theoretical Framework}

\section{Strategic Effectiveness of Accounting information system}

The term "Strategic Effectiveness" is considered as one of the modern terms that emerged in the administrative intellect. Several studies that were conducted in the field have showed that there is a correlation between the strategic effectiveness for organizational businesses and other factors that might affect it. This challenged researchers in the field. However, there are several considerable attempts to find out the most genuine definition of strategic effectiveness among which Boureqia's study which uncovered there dlfactors vis., proficiency, performance and efficiency (Boureqia, 2011).

Accounting information system has certain idiosyncratic features. These features are related to accounting features which result from the economic effect of the events that in return are affected by the activities of the facility. Therefore, accounting information system accepts the economic data resulting from the external or internal operations (Al-Qabani, 2008).

(Al Ali, 2008) proved that accounting information system is not secured from threats of a set of factors that are used in different field for time and efforts saving purposes. The use of accounting information system helped develop the administrative work according the censorship standards of the previous actions.

\section{Objectives of Effectiveness}

Abdul Imam presented a set of objectives that the effectiveness plans to achieve: (Abul-Imam, 2006):

1. Achieving the organization objectives: this means that operational goals with its two kinds; long-term and short-term goals which basically reflect the employees' commitment to achieve these goals.

2. Business organization's adaptation to its environment: business organizations should consider their organizations' quick adaptation to events and environmental enrolment through their strategic management and should also be able to keep the activity and efficiency and make sure that everything related to the organizations is remained under control. 
3. Improving the organization's quality of output: this can be achieved with the help of many factors like overall quality, productivity, employees' proficiency, future productivity schedules and other factors that might contribute to the effectiveness of the organization

\section{E-Commerce}

E- Commerce is defined as the ability to purchase items from where they are exhibited using internet which facilitates the process of exchanging goods, products and services (Hammad, 2009, 90). Below is the principles of E-commerce:

1. The private sector should develop E- commerce to meet the market needs.

2. Participating and using E- commerce should take place according to the standards of the free market, transparency and fair competition.

3. Governments should contribute in creating a stable atmosphere and encouraging it by issuing modern rules that enables the fair recruitment the government's interference should be obvious, transparent, purposeful, impartial, appropriate and flexible. It should also provide technologies without biases and decimation.

4. The private sector should be encouraged to participate in making and creating national and international policies for e- commerce.

5. Insurance of the internationality of e- commerce. By this, the governmental policies that affect ecommerce should be procedure with coordination and cooperation internationally. This permits the homogenous exchange though the borders.

6. Tax treatment should encourage e- commerce in comparison to the tradition commerce and avoid traditional bureaucracy in different countries.

7. The customer's confidentiality and privacy should be secured. Industry, society and their members should participate in securing the digital content according to the standards of the society.

8. Freedom of choice and security of the customer should be granted by companies and business sector.

9. The international environment of data should include confidence through spreading teachings, cooperation and awareness; developing e- commerce, solving conflicts and disputes through organizations of business sector (Al- Amoudi, 2006).

The researchers believe that business organizations intent to employ e- commerce through the network which spread in the entire world to quickly connect countries and areas. Furthermore, these business organizations had to compete with each other to achieve the competitive feature through exchanging products and presenting them to the customers wherever they are with the minimum cost. The thing that proved the wide spreading and flourishing of technologies wide world and removed the obstacles that the countries used to face in quickly and easily exchanging goods and services using the internet.

The researchers also believe that people can purchase what they desire from the internet on which the business organizations usually have websites for which clients get to know the nature and quality of products as well as their companies. The companies usually have cards through which they communicate with their customers and other similar companies to obtain more goods as quickly as possible with the minimum cost. Although, this method of purchasing products is nowadays required, it is also subjected to a number of threats and risks.

These risks can influence the accounting information system, its effectiveness and efficiency. One of these risks is the inability to grant the security and security that should accompany the online purchase procedures given that it is possible for some people to hack the online purchasing websites of companies. This risk also threatens the accounting information system through network. 
The absence of emphasis which means the professional services that can improve the informational input and facilitate the decisions of purchasing and the absence of reliability from the decision makers augment the risks and make it unreliable method of buying goods and products.

The researcher indicates that granting security and reliability leads to the stability of business organizations and helps the society member accept them through the services, goods and products that they present under this frame. This in return will grant the effectiveness and of the organizations and assist them in achieving their objectives.

\section{Previous Studies}

Zualaif's study (2014) aimed at investigating the success degree of the accounting information system and the effect that it has in the stages of dealing with crises in some Jordanian banks. One of her study's results is that accounting information system succeeds in solving and dealing with crises. The study also revealed that the statistical significance was so obvious for the stages that followed the crisis were statistically significant. Zualif recommended for more research to investigate other factors that might affect accounting information system and find out what other possible variables related to crises management.

Dadjeh, (2014) conducted a study to identify the commitment degree in control standards of accounting information system in Islamic Jordanian banks and the employees' awareness of the risks that result from the absence of respecting the control standards and that they should be trained to acquire the skills to confront these risks and deal with them. The study provided a descriptive and analytical approach for these purposes. The statistical analysis proved that the REA approach which is related to the agency should provide information for those who can help to take appropriate decisions. This approach helps analyze the materialistic dimensions of the accounting activities for the purpose of obtaining information related to the events taking place in those banks. The study recommends for further research to investigate other applications of the approach in other banks and present the controlling standards and their relations to accounting information system.

Jabari's study (2013) tackled the importance of the theoretical framework of commerce and e-commerce. It also attempted to list the elements of systems accounting. The study's problem was that the relation between system accounting and E- commerce was not obvious enough. The study arrived at the fact that there is neither shortage in achieving the financial reporting in the operations related to e-commerce nor a decrease in obtaining the financial statements through e- commerce. Jabari recommended decreasing the number of problems that result from applying e-commerce and investigating the relation between ecommerce and other different variables.

Al- Mutairi (2012) attempted to study the ability of accounting information system to measure credit risks in a number of Kuwaiti banks and show the elements of both accounting information system and credit risks. The problem of the study was basically about the lack of research that might establish a relation between accounting information system and credit risks. The study culminated in a statistically significant level timing measurement of the credit risks in Kuwaiti banks and statistically significant effect of accuracy for these risks. In light of the results, this study recommends that Kuwaiti commercial banks should consider the importance of timing for it is one of the important factors that contribute to the success of accounting information system and give much weigh to research about the relation between accounting information system and credit risks.

Al- Abeed (2012) was more interested in his study to find out the extent to which accounting information system might be able to deal with e-commerce and its operations. His study aimed at identifying the elements of accounting information system and e-commerce. The statistical analysis proved that there is a correlation between the accounting systems when dealing with electronic commerce and that there are a 
number of settings that stand in the ability of accounting systems in Kuwaiti banks listed on Kuwait stock exchange. The study also recommended the need to identify the factors of success of e-commerce.

Why is this study different? The previously reviewed study basically dealt with the relation between accounting information system and information technologies (Al- Jaabari, 2013), strategic planning (Foota, Safwa, Samerae 2008, 2009, 2010), and others tackled the information system account (Daaja, 2014). However, the present study is, to the best of the researchers's knowledge, the first to investigate the strategic effectiveness of accounting information system in achieving security in e-commerce which is likely to add something to this field.

\section{Research Methodology}

\section{Population and Sample}

The population of the present study consists of 13 commercial banks in Jordan according to the statistics of the Central Bank. It was applied on managers and their assistants, heads of departments and employees in those thirteen banks. Due to the large number of the population members, the study was limited to four of the most popular Jordanian banks namely: Arab Bank, Bank of Jordan, the Housing Bank and the Cairo Amman Bank which are the most active and effective banks in banking operations, with the number of individuals and employees that reaches 1236. A simple random sample was selected from the total number of members of the study population by (25\%) which is 3.9 of the total number of population. A questionnaire was used as tool to collect data. 309 questionnaires were distributed among the sample of the study, 9 questionnaires were rejected for meeting the rules and 300 were included in study results analysis. The ratio of questionnaires that were recovered and were appropriately good for analysis constituted the percentage (97\%), which is acceptable for the purposes of achieving the objectives of the study.

\section{Data Collection Methods}

The researchers used two types of data. They are indicated below:

1. Secondary Data: through using references like periodicals, books and magazines, the Internet and other research sites in order to produce a theoretical literature related to the subject of the study.

2. Primary Data: data collected through the questionnaire of the study. The researchers made sure that the primary data is reliable, valid and appropriate to serve the purposes of the present study.

\section{Statistical Analysis Methods}

Data was analyzed using the statistical analysis program SPSS. The analysis procedures were conducted as follows:

1. Testing the Reliability of the tool of the study: Cronbach Alpha was used to measure the reliability of the questionnaire's statements and the internal consistency among the responses of the respondents which was $91 \%$, and this value is acceptable because it is higher than $60 \%$ so the results could be generalized.

2. Frequencies, Mean, and standard deviations.

3. Pearson correlation equation.

4. Analysis of variance.

5. T-test

\section{Hypotheses Testing Results}

Based on the theoretical framework and field study, the researchers reached the following results: 
Hypothesis 1 Results: There are no statistically significant differences at the level of significance $(\alpha=$ 0.05 ) for the strategic effectiveness of accounting information system in commercial banks. Therefore, The questions "What is the level of strategic effectiveness in Jordanian banks?" was answered.

It was found that the accounting averages for the level of strategic effectiveness of accounting information systems in Jordanian commercial banks was at the macro level to a medium degree. The activation of strategic effectiveness raises a high level of profitability, increases the capacity of distinctive services and products, and further exploits the opportunities available to it by the environment to meet the needs

Hypothesis 2 Results: There are no statistically significant differences $(\alpha=0.05)$ in the problems that arise through the application of accounting information systems in commercial banks. This was the answer to the second research question: "What are the problems that can result from applying accounting information system in Jordanian banks?"

The general average of the problems that arise through the application of accounting information systems in Jordanian commercial banks based on inputs, outputs and operations is medium.

Hypothesis 3 Results: There are no statistically significant differences $(\alpha=0.05)$ in the degree of personal practice of e-commerce in Jordanian commercial banks. This was the answer to the third research question "To what extent do personnel practice E- commerce in Jordanian banks?" The analysis showed that the general average of the security dimension after the confirmation and after reliability in the practice of individuals for e-commerce in Jordanian commercial banks came to a medium degree.

Hypothesis 4 Results: Is there a statistically significant relationship at the level of significance $(\alpha=0.05)$ for the strategic effectiveness of accounting information systems and achieving security in the light of electronic commerce? The statistical analysis, Beta and T- test confirmed that the independent variable (strategic effectiveness) has an effect on the dependent variable (achieving security in e-commerce), in terms of the beta coefficients of this variable as shown in the table and in terms of value $(\alpha=0.05)$ for the strategic effectiveness of the accounting information systems and the achievement of security in the light of e-commerce, and that the alternative hypothesis that states that there is a statistically significant relationship at Moral level $(\alpha=0.05)$ for the strategic effectiveness of accounting information systems and security in the light of electronic commerce should be accepted.

Hypothesis 5 Results: Is there a statistically significant relationship at the level of significance $(\alpha=0.05)$ for the strategic effectiveness of accounting information systems and achieving security in the light of ecommerce due to demographic variables?

The statistical analysis showed the value of $\mathrm{T}(0.853)$ at a level of significance $(0.501)$ which is greater than the level of (0.05). Therefore, we accept the null hypothesis indicating that there is no statistically significant relationship $(\alpha=0.05)$ Accounting and security in the light of e-commerce due to gender.

Statistical analysis showed that there is no statistically significant relationship $(\alpha=0.05)$ for the strategic effectiveness of accounting information systems and the achievement of security in e-commerce due to age. Statistical analyzes showed that there is no statistically significant relationship at the level of significance $(\alpha=0.05)$ for the strategic effectiveness of the accounting information systems and achieving security in the electronic commerce due to the educational qualification. And the absence of a relationship of statistical significance at the level of significance $(\alpha=0.05)$ of the strategic effectiveness of accounting information systems and achieving security in the electronic commerce attributed to the functional experience or to the functional level. 


\section{Recommendations}

In light of the study results mentioned above, the researchers recommends the following for further research:

1. Working on the activation of accounting information systems in the various commercial banks to be able to practice control, protect the property of bank clients and develop the working performance in these banks.

2. Commercial banks should encourage clients to deal with e-commerce to obtain goods and services through these banks in a way that suits the needs of these customers.

3. Establish audit and control committees in commercial banks to enable them to issue financial reports that are fair and credible and satisfy all customers through a distinguished accounting system in these banks.

4. Commercial banks should update the customer information and banking services that they provided whenever necessary which leads to the development of work in these banks.

5. To make use of the results of this study as much as possible in this area of research.

6. Conduct training and qualifying programs for employees in commercial banks, develop their skills in accounting information systems and train them on how to activate e-commerce in these banks.

7. Working to activate the standards of international accounting and audit committees to ensure a secure environment for accounting information systems and electronic commerce in banks.

8. Establishing specialized bodies through which the control of banks can be activated and teach them how they should benefit from the accounting information systems and promote for e-commerce in general.

9. Carry out other studies in other sectors such as the sector of industrial companies or service companies that deal with e-commerce in order to benefit from the results that can be obtained from these studies in developing the concept of electronic commerce.

\section{References}

Abdel-Imam, Hadi, (2006). Organizational Bank and its impact on the effectiveness of banking organizations, Journal of Management Studies, 1 (1), pp. 3-119.

Abdul Sattar, Al Ali, (2008). Introduction to Knowledge Management, Amman: Dar Al Masirah for Publishing and Distribution.

Al- Daaja, Khaled, (2014). Censorship in Computerized Accounting Information Systems, Analytical Study in Commercial Banks in Jordan, Unpublished Phd Dissertation, Damascus University, Damascus, Syria.

Al Mutairi, Sharar (2012). The Role of Electronic Accounting Information Systems in Improving Credit Risk Measurement: An Empirical Study on Kuwaiti Commercial Banks, Middle East University, Amman, Jordan.

Al-Amoudi, Ahmed Abdullah Omar, (2006). The Effect of Electronic Commerce on Auditing, unpublished $\mathrm{PhD}$ thesis, Damascus University, Syria

Al-Obaidi, Jawahar, (2013). The Effect of Creative Direction and Training Strategy on the Performance of KOC Personnel, Unpublished MA Thesis, Middle East University, Amman, Jordan.

Berenson,Mark L,Levine,David M,and Krehbiel ,Timothy C,(2011) "Basic Business statistics: Concept and Application, $12^{\text {th }}$,Prentice Hall.

Bourqaba, Bourguiba, (2011). Distinguishing Efficiency, Effectiveness, and Performance, Published Research, Farhat Abbas University, Summer, Algeria, 1 (1), 2011, pp. 1-14.

Fouta, Sahar, (2008). The Impact of Strategic Planning and Human Resources Planning on the Performance of Public Shareholding Companies in Jordan. Unpublished MA Thesis, Amman Arab University, Amman, Jordan.

Jabri, Majdi (2013). The adequacy of the Theoretical Framework of Accounting under Electronic Commerce, Unpublished PhD Dissertation, the Arab Academy in Denmark, Denmark 
Samarrai, Hashim (2010). The Impact of training strategies to develop human resource resources in the public sector Electricity sector in Iraq model, unpublished master thesis, the Arab Academy in Denmark, Denmark.

Samarrai, Hashim (2010). The Impact of training strategies to develop human resource resources in the public sector Electricity sector in Iraq model, unpublished master thesis, the Arab Academy in Denmark, Denmark.

Tarek, Abdel-Al Hammad. E-Commerce (Concepts, Services, Experiences, Challenges, Technological, Financial, Marketing and Legal Dimensions)

Zuailif, Enam, (2014). The Success of Accounting Information Systems and Its impact in the Stages of Crisis Management, Unpublished research, Faculty of Economics and Administrative Sciences, AlZaytoonah University, Amman, Jordan, pp. 1-33. 